\title{
Sistemas de publicação na internet sob a lógica de simondon
}

Resumo

A proposta deste artigo é compreender como um sistema de publicação na internet pode ser pensado e como seus elementos se relacionam entre si, desde a lógica de pensamento do filósofo francês Gilbert Simondon (1958) que sistematiza o objeto técnico em elemento, indivíduo e conjunto, partindo do nível mais simples ao mais composto. Em função dos sistemas de publicação serem mecanismos diversificados que, dependendo do aspecto analisado, podem ser considerados um software, uma ferramenta, um sistema, um ambiente ou até mesmo uma plataforma, a análise será efetuada de acordo com a lógica proposta, do ponto mais elementar ao mais complexo.

Palavras-chave:

Internet, sistema de publicação, Simondon 


\section{Publishing' $s$ systems on the Internet under the logic of simondon}

\section{CARLA SCHWINGEL}

Keywords: Internet, publishing system, Simondon

\section{Abstract}

The purpose of this paper is to understand how a system for publishing on the Internet can be thought of and how its elements relate theirself, since the logic of thought of the French philosopher Gilbert Simondon (1958). Simondon systematizes the technical object in element, subject and joint, starting from the simplest level to the more composed. The system of publication can be provider of diverse mechanisms, depending on the aspect analyzed, can be considered software, tool, system, environment or even a platform; the analysis will be conducted in accordance with the proposed logic, the point most basic to complex. 
"A definição dialética da máquina coloca-a, tal como outro produto humano qualquer, na perspectiva das contradições humanas que destina resolver".

Álvaro Vieira Pinto

Os sistemas de publicação são sistemas de gerenciamento desenvolvidos ou customizados para a produção de conteúdos no ciberespaço. Programas e plataformas com interfaces amigáveis que não exigem conhecimento de linguagens de programação. Com eles, o usuário internet pode publicar livremente informações em texto, imagens estáticas e em movimento, pode editá-las online e interagir com outros conteúdos. São os sistemas blogs, as funcionalidades dos serviços de hospedagem de fotos, vídeos e áudios, os aplicativos e ambiências das redes sociais.

Para uma compreensão mais ampla de sistemas de publicação, procura-se, primeiramente, discutir as noções dos elementos que, através de um aporte filosófico, dos sistemas de informação e da engenharia de softwares, compõem e estruturam ferramentas, conjuntos, sistemas, ambientes tecnológicos.

Tendo como ponto de partida o estudo de Simondon (1958) que problematiza a origem da tecnicidade na civilização industrial do ocidente para compreender como a relação homem-máquina se estabelece em termos filosóficos, procura-se atualizar sua lógica visando buscar uma sistematização para os componentes de um sistema de gerenciamento de conteúdos na internet. A escolha deste filósofo para fundamentar o aporte teórico deste trabalho deve-se ao fato de ter desenvolvido um sistema completo de pensamento para explicar a tecnicidade e os objetos técnicos ${ }^{1}$.

Os objetos técnicos, no momento dos estudos de Simondon (1958) começavam a estar presentes na vida cotidiana, no 
mundo industrial. Portanto, sua análise recai sobre válvulas, motores, dínamos. Porém, ainda hoje - quando as ações diárias de trabalho, comunicação e interação ocorrem em grande maioria através de mecanismos tecnológicos -, as inferências e lógica de pensamento deste filósofo podem ser perfeitamente aplicadas tendo em vista a compreensão do funcionamento da lógica técnica em sua utilização prática, em sua concretude, nos mecanismos técnicos em si.

O objeto técnico é sujeito a uma gênese, mas é difícil definir a gênese de cada objeto técnico, porque a individualidade dos objetos técnicos altera-se durante a gênese, pode-se apenas definir os objetos técnicos por seu pertencimento a uma espécie técnica; as espécies são fáceis de distinguir sumariamente, pelo uso prático, tanto que se aceita apreender o objeto técnico pelo fim prático a que responde, mas ele se agita de uma especificidade ilusória, porque nenhuma estrutura fixa corresponde a um uso definido ${ }^{2}$ (SIMONDON, 1958, p.19).

A tecnicidade, para Simondon (1958, p.52-78), significa o objeto em si, o que faz, o que representa, como atua, ou seja, o "grau de concretização" de determinado aparato. A tecnicidade seria a vinculação entre os diferentes elementos de um sistema, sua funcionalidade e, em última instância, o que faz determinado objeto técnico ser aplicável ao mesmo tempo em que evidencia novas funcionalidades.

O inerente da tecnicidade para os objetos técnicos é provisório; ele somente constitui um momento do devenir de sua gênese. Porém, de acordo com esta hipótese, a tecnicidade nunca deve ser considerada como realidade isolada, mas como parte de um sistema. Ela é realidade parcial e passageira, resultado e princípio da gênese. Resultado de uma evolução, é depositária de um poder evolutivo, precisamente porque contém como solução de um primeiro problema, o poder de ser uma mediação entre o homem e o mundo ${ }^{3}$. (SIMONDON, 1958, p.157).

De acordo com sua hipótese, em termos filosóficos, tecnicidade é "o grau de concretização do objeto"4 (SIMONDON, 1958, p.72). Pode ser considerada como uma característica positiva do elemento, análoga à auto-regulação exercida pelo meio associado ao indivíduo técnico. É a tecnicidade que faz com que o elemento seja realmente produzido por um con- 
junto, embora ele mesmo não seja um conjunto ou indivíduo, e o libera para que novos indivíduos possam ser constituídos.

Com vistas a compreender como um sistema de publicação pode ser pensado e como seus elementos se relacionam entre si, utilizaremos a lógica de Simondon (1958) que sistematiza o objeto técnico em elemento, indivíduo e conjunto, partindo do nível mais simples ao mais composto. Em função dos sistemas de publicação se constituírem mecanismos diversificados que, dependendo do aspecto analisado, podem ser considerados um software, uma ferramenta, um sistema, um ambiente ou até mesmo uma plataforma, a análise será efetuada de acordo com a lógica da proposta do filósofo francês, ou seja, do ponto mais elementar ao mais complexo.

\section{Elementos ou ferramentas}

O elemento, para Simondon (1958, p.175), é o objeto fabricado. "O elemento, para o pensamento técnico, é mais estável, melhor conhecido, e de qualquer maneira mais perfeito do que o conjunto; ele é realmente um objeto, considerando que o conjunto sempre permanece em certa medida inerente ao mundo ${ }^{5}$. No sentindo dado pelo autor, quanto mais um elemento de um objeto exacerba, potencializa sua função em relação ao meio associado, mais se configura a perspectiva de um novo objeto tendo em vista uma função específica. Ou seja, pode-se pensar em uma determinada ferramenta integrada a um sistema de publicação, que foi desenvolvida visando cumprir uma tarefa estabelecida (por exemplo, a ação de incluir associações (links) a uma publicação); porém, com a utilização, seus usuários percebem que somente associar vinculações não é o suficiente, já que tipos distintos de associações se fazem necessários. Então, ao potencializar a função "vinculações", constituem-se outros objetos que são as vinculações internas, as externas e as janelas explicativas, transformando, assim, o sistema e individualizando cada vez mais as ferramentas.

Para Simondon (1958, p.73), os objetos técnicos são os seres técnicos em si, porém não surgem do nada, são resultantes das necessidades de processos que se constituem na própria tecnicidade.

A tecnicidade pode ser considerada como uma característica positiva do elemento, análoga à auto-regulação exercida pelo meio associado no indivíduo técnico. A tecnicidade em nível do elemento é a concretização, que faz com que o elemento 
seja realmente produzido por um conjunto, embora ele mesmo não seja um conjunto ou indivíduo. Esta característica o torna destacável do elemento e o libera para que novos indivíduos possam ser constituídos ${ }^{6}$.

E no domínio técnico, este objeto, precisamente por ser fabricado, é separável do conjunto que o produz. E esta independência e separatividade é outro dos motivos de sua aproximação e associação como ferramenta constituinte de um sistema de publicação.

Apesar de que o filósofo não considerava a ferramenta análoga ao elemento técnico, mediante a complexidade e avanço dos conjuntos técnicos de hoje em dia pode-se considerar assim, pois, conforme afirma:

Tudo se passa como se a ferramenta em sua totalidade fosse feita de uma pluralidade de zonas de funcionamento diferentes, reunidas umas e outras. Não é feita somente de forma e matéria; é feita de elementos técnicos elaborados de acordo com certo esquema de funcionamento e reunidos em uma estrutura estável para operar a fabricação. A ferramenta concentra nela o resultado do funcionamento de um conjunto técnico. ${ }^{7}$ (SIMONDON, 1958, p.72).

A ferramenta, ainda de acordo com o filósofo, seria o instrumento (a diferença entre ferramenta e instrumento consiste em que a primeira altera o mundo e o segundo permite aferir o mundo) que permite prolongar e armar o corpo para realizar um gesto ou adaptá-lo para obter melhor percepção. Ou seja, as ferramentas são elementos dispostos de acordo com determinado funcionamento, porém este funcionamento pode ser isolado (com o uso individual de um ferramental) ou de forma associada (quando passaria a ser um indivíduo ou sistema). Uma ferramenta é considerada, de forma consensual e dicionarizada, como um utensílio ou um conjunto de utensílios e, para a Informática, pode ser entendida como um software ou um aplicativo, isto é, um tipo de programa que resolve determinado problema (SOMMERVILLE, 2003).

O sentido que estamos dando à ferramenta neste trabalho é uma associação do elemento de Simondon (1958) com o de aplicativo, da Engenharia de Softwares (SOMMERVILLE, 2003). Assim, uma ferramenta é um objeto técnico independente, com uma função específica, que pode ser integrado ou retirado do sistema. 


\section{Indivíduos ou sistemas}

No nível seguinte de complexidade, Simondon (1958) propõe o indivíduo técnico que é composto pelo elemento e pelo meio associado a ele, ou seja, envolve processos relacionais. Os indivíduos técnicos dependem, em certa medida, das características dos elementos que eles introduzem e fazem funcionar. Para o autor, só existirá indivíduo técnico quando o meio associado é uma condição prévia e determinante para seu funcionamento.

O princípio da individualização do objeto técnico pela causalidade recorrente do meio associado permite pensar com mais clareza certos conjuntos técnicos e saber se pode ser tratado como indivíduo técnico quando o meio associado existe como condição sine qua non para seu funcionamento; no caso contrário, há conjuntos técnicos. ${ }^{8}$ (SIMONDON, 1958, p. 61).

A individualização só pode acontecer em cada uma das partes de um todo, pois é cada uma delas que estabelece fisicamente a conexão com o meio associado e, portanto, individualizado, gerando as condições para que determinado componente se sobressaia em sua função, apontando uma nova perspectiva de invenção. Assim, os indivíduos técnicos resultam, de certa forma, das características dos elementos (ferramentas, conforme está se propondo) que eles introduzem e fazem funcionar. Pretende-se, então, relacionar tal noção a de sistemas, já que estes são compostos por ferramentas e somente possuem sentido técnico em função de seu meio associado.

Para a Ciência da Computação, sistemas de informação são tanto as ferramentas que os compõem associadas aos aspectos gerenciais quanto às tecnologias que serão utilizadas (SOMMERVILLE, 2003). Um sistema corresponde à modelagem de uma solução tecnológica para o isolamento de um problema, estando vinculado a uma determinada tecnologia e a processos gerenciais. Sistema, sob o ponto de vista de Sommerville (2003), relaciona-se a um determinado paradigma computacional, que pode ser funcional, de orientação a objeto, de janela ou modular, e que define os tipos de entidades e de relações.

Um paradigma de programação pode fornecer ou determinar a visão que os programadores precisam ter para estruturarem e executarem os programas. "Um paradigma determina a maneira de se perceber o universo e quais são os 
elementos que o constituem. Partindo deste fato, pode-se concluir que um paradigma de software é um instrumento utilizado para modelagem e percepção computacional do universo" (MENDES, 2000, p.02). 1) No funcional, os programas são escritos por meio de funções, expressões e declarações. As variáveis, comandos e efeitos colaterais são excluídos e programam especificando o que se quer construir e não como deve ser construído, a maioria das linguagens são implementadas por interpretação, ou seja, os programadores abstraem o programa como uma seqüência de funções executadas de forma empilhada (LIFO - Last In, First Out) (LEITE, 2004). 2) No paradigma de orientação à objeto, ocorre a composição e interação entre diversas unidades de software, os denominados objetos. A análise e projeto orientados a objetos têm como meta identificar o melhor conjunto de objetos para descrever um sistema de software. O funcionamento deste sistema se dá através do relacionamento e troca de mensagens entre estes objetos. 3) No paradigma de janela, os recursos são associados de forma a se adaptarem e a agregarem em espaços que vão sendo agregados; 4) No paradigma modular, as rotinas de programação são programadas através de módulos interligados através de uma interface comum (SOMMERVILLE, 2003). Para o pensamento matemático, de forma sistemática, os paradigmas computacionais abrangem os convencionais (imperativo e procedimental) e não convencionais (lógico, orientado a objetos e orientado a agentes) (MENDES, 200o).

São as entidades de software, ou seja, seus conjuntos de componentes que vão interagir. Tais entidades e relações entre elas, isto é, o fluxo de dados depende do paradigma, pois é a forma de representação desses objetos e entidades que definirá como os dados serão capturados, bem como o comportamento do sistema (SOMMERVILLE, 2003). Portanto, sob o ponto de vista técnico, um sistema pode ser compreendido como "uma coleção significativa de componentes inter-relacionados, que trabalham em conjunto para atingir algum objetivo" (SOMMERVILLE, 2003, p.18). Uma das características fundamentais de um sistema, de acordo com a Engenharia de Softwares, é que as propriedades e o comportamento dos componentes devem estar intrinsecamente interligados, ou seja, "o funcionamento bem sucedido de cada componente do sistema depende do funcionamento de alguns outros componentes" (SOMMERVILLE, 2003, p.18).

A hierarquização e a complexidade são outras das características intrínsecas dos sistemas (SOMMERVILLE, 2003). Um 
inclui outros, denominados de subsistemas, sendo um articulado ao outro, em um processo que define as prioridades para determinado fluxo de dados. Como cada sistema é composto por vários, a complexidade é inerente e derivada.

As complexas relações entre os componentes em um sistema significam que o sistema é mais do que simplesmente a soma de suas partes. Ele tem propriedades que são do sistema como um todo. Essas propriedades emergentes não podem ser atribuídas a nenhuma parte específica do sistema. Pelo contrário, elas emergem somente quando o sistema como um todo é considerado (SOMMERVILLE, 2003, p.18).

Tais propriedades, que sobrepõem o sistema e não podem ser analisadas separadamente, podem ser comparadas e associadas à própria noção de tecnicidade de Simondon (1958). E tais percepções parecem encontrar ressonância na Teoria Sistêmica, pois tanto para a tendência organicista quanto para a mecanicista a soma das partes é maior do que o todo em um sistema (VASCONCELOS, 2002). Para esta teoria, sistema é um conjunto de objetos interligados, no qual a complexidade e a riqueza das conexões designam seus graus de "sistematicidade", com fronteiras arbitrárias que dependem de um ponto de vista.

A Cibernética ${ }^{9}$, cuja tendência é mecanicista, considera como seu objeto de estudo mais interessante aqueles sistemas nos quais os fatores aleatórios possuem um importante papel; bem como tem como principais temas a auto-regulação, a auto-reprodução, a evolução e a involução dos sistemas sociais $^{10}$. As estruturas sistêmicas mecanicistas buscam uma ordem; a aleatoriedade sempre é interpretada como um fator que inevitavelmente dirige-se ao equilíbrio com o todo. Para a tendência organicista, sistema é "um complexo de elementos em interação ou um conjunto de componentes em estado de interação. [...] Os sistemas podem ser definidos por famílias de equações diferenciais e podem ser encontradas muitas propriedades importantes dos sistemas em casos gerais e mais especiais" (BERTALANFFY, 1975, p.62).

Assim, pretende-se aproximar a noção de sistema, em função de sua dependência do meio, com o conceito de indivíduo de Simondon (1958) e passá-lo a compreender com a possibilidade de ser múltiplo, complexo, auto-organizativo, integrado e reflexivo, de acordo com a tradição acadêmica na área da Comunicação proposta por McLuhan (1969), consoli- 
dada por Luhmann (1996, 2005), e vinculada aos aspectos da auto-organização e do pensamento complexo acrescidos por Maturana (2001) e Morin (2001, 2005) com a teoria da complexidade e seus princípios dialógico, de recursividade organizacional e de representação hologramática.

O interessante da abordagem do autor francês é a atualização do conceito e a vinculação da moderna teoria geral dos sistemas aplicada a grupos antropossociais, à Comunicação. Em função da complexidade como o fator essencial que mantém o sistema, para Morin (2005), o próprio conceito passa a ser questionado e se expande. Ao definir o sistema como uma inter-relação de elementos que constituem uma entidade ou unidade globalizante, e ao vincular as ideias de totalidade através da organização, o autor francês destaca que as inter-relações entre elementos, acontecimentos e indivíduos com caráter regular ou estável, tornam-se organizacionais. De acordo com essa idéia, "a análise de um sistema não se restringe ao sistema em si, mas vai exigir uma abordagem que dê conta do seu meio ambiente" (HENN, 1996, p.62). Morin (2005, p.175) propõe as seguintes distinções para caracterizar os sistemas:

Sistema, para todo sistema que manifeste autonomia e emergência ao que lhe é exterior. Subsistema, para todo sistema que manifeste subordinação em relação a um sistema no qual ele é integrado como parte. Supra-sistema, para todo sistema controlando outros sistemas, mas sem integrá-los entre si. Ecossistema, para o conjunto sistêmico cujas inter-relações e interações constituem o ambiente do sistema que aí está englobado. Metassistema, para o sistema resultante das inter-relações mutuamente transformadoras e englobantes de dois sistemas anteriormente independentes. De fato, as fronteiras entre estes termos não são claras e eles mesmos são substituíveis entre si, de acordo com a focalização, o recorte, o ângulo de visão do observador sobre a realidade sistêmica em consideração.

Assim, quando um objeto de análise se configura como um sistema, as questões de definição e de limitação do campo de abrangência do fenômeno geralmente estão presentes. É nesse sentido, que se propõe a vinculação da noção de sistema a de indivíduo técnico de Simondon (1958) com vistas a contribuir para a delimitação dos limites do fenômeno observado. 


\section{Conjuntos técnicos ou ambientes}

No terceiro nível de complexidade, a proposição é a dos conjuntos técnicos (SIMONDON, 1958), que seriam os indivíduos mais o contexto externo, ou seja, quando o meio associado não é uma condição necessária para o funcionamento. Os conjuntos técnicos são vários objetos associados sob determinada compreensão contextual.

O princípio da individualização dos objetos técnicos em um conjunto e de seus sub-conjuntos trata da causalidade recorrente no meio associado; todos os objetos técnicos que têm uma causalidade recorrente em seus meios associados devem ser separados uns dos outros e ser conectados de maneira a manter esta independência dos meios associados uns em relação aos outros. ${ }^{11}$ (SIMONDON, 1958, p. 63).

Portanto, neles há elementos e indivíduos vinculados, mas não dependentes uns dos outros. Nesse sentido, pode-se efetuar uma vinculação com a noção de ambiente, onde sistemas e ferramentas interagem de forma independentes umas das outras e, como bem nos lembra o pesquisador do jornalismo digital brasileiro Marcos Palacios (2003), as noções de sistema e de ambiente são praticamente indissociáveis na Teoria Sistêmica. A fluidez dessas fronteiras faz com que ocorra um intercâmbio entre subsistemas e ambientes, e não seria possível concebê-los como pólos estanques. Portanto, os ambientes são inevitavelmente mais complexos que os sistemas que os compõem, e a delimitação de determinado ambiente ocorre sempre em função destes. Nesse sentido:

A Internet, no contexto do Ciberespaço, é melhor caracterizada não como um novo medium, mas sim como um sistema que funciona como ambiente de informação, comunicação e ação múltiplo e heterogêneo para outros sistemas. Sua especificidade sistêmica seria a de constituir-se, para além de sua existência enquanto artefato técnico ou suporte, pela junção e/ou justaposição de diversos (sub)sistemas, no conjunto do ciberespaço enquanto rede híbrida (PALACIOS, 2003, p.o8).

O ambiente tecnológico da internet, "como uma articulação complexa e dinâmica de diversos formatos jornalísticos, em diversos suportes, 'em convivência' (e complementação) no espaço mediático" (PALACIOS, 2003, p.03), pode ser 
aproximado à noção apresentada por Gillmor (2004) quando afirma ser este um fantástico ambiente de publicação para os jornalistas. Ou seja, com a interatividade que as tecnologias da informação e da comunicação propiciam, estruturas diferenciadas daquelas definidas pelo pensamento baseado na cultura do impresso passaram a ser vislumbradas pelos usuários, comunicadores e produtores de conteúdos. Estas noções começaram a ser discutidas conceitualmente com o rádio com o clássico texto "Teoria de la radio" (de 1927-1932) de Bertold Brecht sobre as possibilidades interativas deste meio de comunicação, um anúncio e antevisão do que a tecnologia digital propiciaria.

De acordo com McLuhan (1989), a noção de espaço acústico alterou os padrões de orientação da população, em função de se deixar um ambiente no qual os objetivos eram linearmente concebidos para outro que seria um campo de energias polarizadas. A tentativa de compreensão do meio, como tratado pelo pesquisador canadense, delimitou um subcampo na comunicação com vistas a compreender o meio de comunicação em seu entorno e não em sua relação mediática.

A ideia aqui apresentada é a de um ambiente de produção de conteúdos comunicacionais, com o desenvolvimento de sistemas distintos voltados para as etapas produtivas, de acordo com o sugerido por Palacios (2003, p.09):

Na medida em que a Internet caracteriza-se por sua situação de utilização simultânea, enquanto ambiente, por múltiplos (sub)sistemas sociais, a enorme diversificação de usos observados na rede decorre de demandas próprias, específicas, de cada um dos (sub)sistemas sociais que tem na Internet parte de seus ambientes de funcionamento, levando por exemplo à criação de aplicativos específicos, que são posteriormente generalizados e utilizados por outros sub-sistemas.

Propõe-se, então, a compreensão do ambiente de produção de conteúdos hipertextuais tendo em vista a publicação jornalística informativa como um conjunto:

1) de subsistemas de busca, pesquisa, correlação de dados, compondo um sistema de apuração;

2) de subsistemas de composição, edição e disponibilização de dados, compondo um sistema de publicação;

3) de subsistemas integrados para a distribuição das informações em diferentes plataformas e com a aplicação de tecnologias também diferenciadas, compondo um sistema de circulação. 
Então, propõe-se pensar em termos de ferramenta, sistema e ambiente, no sentido de uma evolução de tecnologias complexas aos fazer-se referência aos sistemas de produção de conteúdos na internet. E, considerando-se, os acontecimentos com o passar do tempo, concorda-se com Simondon (1958) que elementos (ferramentas), indivíduos (sistemas) e conjuntos técnicos (ambientes) sempre existiram, mesmo entre os povos que não possuíam indústria (sequer informatização), e sua perpetuação depende inexoravelmente dos elementos, pois tanto indivíduo quanto conjunto são temporários ou mesmo ocasionais já que conformados a partir de contextos mais amplos, os do próprio funcionamento/paradigma, no caso dos indivíduos/sistemas; e institucional ou sócio-cultural, no caso dos conjuntos/ambientes.

É nesse sentido contextual dos sistemas de gerenciamento de conteúdos compostos por elementos/ferramentas de acordo com um paradigma e regras de funcionamento que os sistemas de publicação são analisados, ou seja, como compostos por ferramentas que alteram o sistema, modificando-o, tornando-se permanentes ou não para uma determinada configuração. Os sistemas são temporâneos, pois respondem e são formatados a partir de um contexto, o que só vem ratificar, do ponto de vista deste trabalho, a importância de projetos específicos de sistemas de produção para a composição de narrativas interativas que vinculem conteúdos multimídia no ciberespaço. E que considerem os aspectos sócio-culturais, institucionais e paradigmáticos do processo de produção em ambientes digitais, em termos teóricos, práticos e deontológicos.

\section{Referências}

BAUDRILLARD, J. Simulacros e Simulação. Lisboa: Antropos 1991.

. Tela total. Porto Alegre: Sulinas, 1997. . A transparência do mal. Campinas: Papirus, 1992.

BERTALANFFY, L. V. Teoria geral dos sistemas. Petrópolis: Vozes, 1975.

BRECHT, B. Teoría de la radio. In: BRECHT, B. El compromiso en literatura y arte. Barcelona: Ediciones Península, 1973, p. 81-92.

HENN, R. Pauta e Notícia. Canoas: Editora da Ulbra, 1996.

LUHMANN, N. A realidade dos meios de comunicação. São Paulo: Paulus, 2005. 
. Introducción a la teoría de sistemas. Mexico: Universidad Iberoamericana, 1996.

McLUHAN, M. Os meios de comunicação como extensões do homem. São Paulo: Cultrix, 1969.

MENDES, S. C. Metodologias de design de código e armazenamento de dados: Linguagens Funcionais em Matemática Discreta. Trabalho apresentado na Semana Acadêmica do Programa de Pós-Graduação em Computação da UFRGS. 200o. Disponível em: http://www.inf.ufrgs.br/pos/SemanaAcademica/Semanazooo/SimoneMendes. Acessado em 30 de março de 2008.

MORIN, E. O método 4: as idéias, habitat, vida, costume e organização. Porto Alegre: Sulina, 2001.

O Método 1: a natureza da natureza. Porto Alegre: Sulina, 2005.

PALACIOS, M. Fazendo jornalismo em redes híbridas: notas para discussão da Internet enquanto suporte mediático. Lista JnCultural, fev 2003. Disponível em: www.fca.pucminas.br/jornalismocultural/m_palacios.doc, acessado em junho de 2004.

PINTO. Álvaro Vieira. O conceito de tecnologia. Rio de Janeiro: Contraponto, 2005a.

. O conceito de tecnologia. Rio de Janeiro: Contraponto, 2005b.

SANTOS, Milton. natureza do espaço: técnica e tempo - razão e emoção. São Paulo: Hucitec, 1996.

SCHWINGEL, C.A. Sistemas de produção de conteúdos no ciberjornalismo: a composição e a arquitetura da informação no desenvolvimento de produtos jornalísticos. Programa de Pós-Graduação em Comunicação e Cultura Contemporânea da Universidade Federal da Bahia, Salvador, 2008a. Tese.

. Ciberjornalismo. São Paulo: Paulinas, 2012.

SIMONDON, Gilbert. Du mode d'existence des objets techniques. Paris: Editions Aubier, 1958.

SOMMERVILLE, I. Engenharia de Software. São Paulo: Addison Wesley, 2003.

NOTAS

1. Diversos autores contemporâneos, como Santos (1996) e Baudrillard (1991; 1992; 1997), analisam tecnologia e comunicação. Além de Simondon (1958), outros filósofos foram estudados, como Spengler $(1958 ; 1993)$, Heidegger (1958); Leroi Gourhan (1964); Ellul (1968); Munford (1964; 1970), Moscovici (1972), Wiener (1973), Sfez (1992), Steigler (1994), Séris (1994), Duarte Rodrigues (1999), Flichy (2003), Chabot e Hottois (2003) e Vieira Pinto (2005a, 2005b). 
2. Livre Tradução: L'objet technique est soumis à une genèse, mas il est difficile de definer la genèse de chaque objet technique, car l'individualité dês objets techniques se modifie au cours de la gênese; on ne peut que difficilement definir lês objets techniques par leur appartenance à une espèce technique; lês espèces sont faciles à distinguer sommairement, pour l'usage pratique, tant qu' on accepte de saisir l'objet technique par la fin pratique à laquele il répond, mais il ságit là d'une spécificité illusoire, car aucune structure fixe ne correspond à un usage défini.

3. L.T.: L inhérence de la technicité aux objets techniques est provisoire; elle ne constitue qu'un moment du devenir génétique. Or, selon cette hypothèse, la technicité ne doit jamais être considérée comme réalité isolée, mais comme partie d'un système. Elle est réalité partielle et réalité transitoire, resultat et príncipe de genèse. Rèsultat d'une évolution, elle est dépositaire d'un pouvoir évolutif, précisement parce qu'elle possède comme solution d'un premier problème le pouvoir d'être une médiation entre l'homme et le monde.

4. LT: le degré de concretisation de l'objet.

5. L.T.: L'élément, dans la pensée technique, est plus stable, mieux connu, et en quelque maniére plus parfait que l'ensemble; il est réellement um objet, alors que l'ensemble reste toujours dans une certaine mesure inhérent au monde.

6. L.T.: La technicité peut être considérée comme un caractere positif de l'élément, analogue à l'auto-régulation exercée par le milieu associe dans l'individu technique. La technicité au niveau de l'élément est la concrétisation; elle est ce qui fait que l'élément est réellement élément produit par un ensemble, mais non ensemble lui-même ou individuo, cette caractéristique le rend détachable de l'élément et le libere pour que de nouveaux individus puissent être constitués.

7. L.T.: Tout se passe comme si l'outil dans as totalité était fait d'une pluralité de zones fonctionnellement différentes, soudées lês unes aux autres. L'outil n'est pás fait seulement de forme et de matière; Il est fait d'éléments techniques elabores selon um certain schème de fonctionement et assemblés en structure stable par l'operation de fabrication. L'outil recueille en lui le résultat du fonctionnement dun ensemble technique.

8. L.T.: Le príncipe de l'individualisation de l'objet technique par la causalité récurrente dans le milieu associe permet de penser avec plus de clarté certains ensembles techniques et de savoir s'il faut lês traiter comme individu technique lorsque le milieu associe existe comme condition sine qua non de fonctionnement, alors qu'il y a ensemble dans le cas contraire.

9. Norbert Wiener, a partir da palavra grega Kubernetics (timoneiro), conceitua cibernética como todo o campo do controle e da teoria da comunicação, tanto aplicado à máquina como ao animal. Ver: Wiener, Norbert. Cybernetics. Cambridge, Mass., MIT Press, 1948, p.15-47.

10. Para noções básicas, ver: EPSTEIN, Isaac. Cibernética. São Paulo: Editora Ática, 1986.

11. L.T.: Le príncipe d'individualisation dês objets techniques dans un ensemble est donc celui dês sous-ensembles de causalité récurrente dans le milieu associe; tous lês objets techniques qui ont une causalité récurrente dans leus milieu associe doivent être separes lês uns dês autres et connectés de manière à maintenir cette indépendance dês millieux associes lês uns par rapport aux autres.

Recebido em: 05/01/12

Aceito em: 05/01/12 


\section{CARLA SCHWINGEL}

caruschwingel@uol.com.br

Jornalista (UFRGS), mestre em cibercultura e doutora em ciberjornalismo pelo Programa de Pós-Graduação em Comunicação e Cultura

Contemporâneas (UFBA). Pós-doutoranda em Fotônica e Novas

Mídias na Universidade Mackenzie - SP. Lattes: http://lattes.cnpq.

br/0205151030500381 